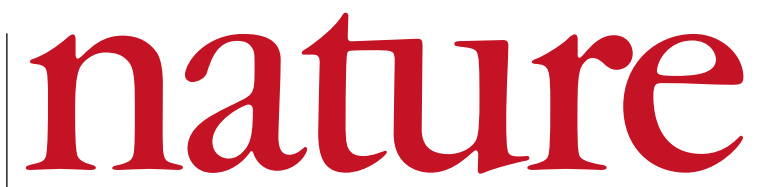

20 February 2003 Volume 421 Issue no 6925

\title{
How to publish in Nature
}

Hopeful authors of research papers will help themselves by reading our new Guide to Authors before submission. This also highlights the need and opportunity to communicate more effectively with important non-specialist audiences.

ditors at Nature frequently receive passionate pleas from aspiring authors that publication of their paper is crucial for a grant, a position or for some other prospect. The scientific profession to which these authors belong is locked into a reward system based excessively on quantitative assessments, such as the number of papers published in journals that have a particular impact factor.

This broadening of the role of leading journals raises the stakes for authors. They are used to writing for fellow scientists within the discipline who will pore over every word of the methods section and have little patience with perceived hyperbole about the greater meaning of the results. Publication in these journals also requires authors to make the most of the superb opportunity to communicate to an audience far wider than their immediate peers.

Authors who submit to an interdisciplinary journal have to consider a second readership: scientists outside the discipline. These scientists read the paper for other reasons, such as a simple interest in the breadth of science, teaching, applying a new technique or observation to their own system, or ambitions to apply their discipline's armoury to the scientific challenge discussed. Nature has long guided its authors in this process, as their sometimes excruciatingly technical initial manuscripts travel the road towards publication in a more readable form. But authors can do more for intelligibility themselves at the outset, by showing papers to researchers with other backgrounds before submitting.

Nature provides researchers with other help, too, in the form of greatly increased efficiency and transparency in its handling of papers, via a new web-based submission system that allows authors to track the progress of their papers through the refereeing process. We have also revised our Guide to Authors (see page 868 ) to provide clearer advice about how to write a paper. And we now actively encourage authors to be transparent by identifying which co-author contributed what to the work, in a section published at the end of the paper, and ensure that all authors are signed up to our principles of data access and materials sharing (see www.nature.com/nature/ submit/policies for details of these and other improvements).

In addition, Nature invites authors to help us present their results to diverse audiences. In submitting a paper, authors are now asked for two summaries: one to summarize their work for readers (mainly scientists and editors), and another to crystallize the importance of their work for the general public. Nature will draw on these in the presentation and promotion of its papers.

Researchers are increasingly recognizing their duties towards broader readerships, not least the media and the more scientifically interested public. And where science can get distorted or smothered, researchers cannot sit back and let the journals do all the work for them. True, Nature's role is to publish the most innovative and influential papers that scientists can produce, and to present these results to the public. But it is the responsibility of researchers to seize the initiative, and communicate their knowledge and uncertainties to avoid misconceptions - and sometimes even to campaign to get science's messages across. Nature will continue to guide the media to authors of papers so that they are centrally involved in these opportunities.

\section{In support of xeno-optimism}

Despite recent gloom, there are worse things on which to spend personal wealth than a hunt for intelligent extraterrestrials.

$\mathrm{H}$ ow easy it is to scoff at 'desperate' seekers of aliens, as the science-fiction writer Brian Aldiss did in these pages two years ago (Nature 409, 1080; 2001). He touched some nerves: aliens are indeed as real as ghosts or numerous deities (in other words, they continue to be purely imaginary); their fictitious portrayals impede understanding; their air of being the product of scientific thinking is indeed spurious. But when all was said and done, his put-down, although erudite, was ultimately no more than a stimulating polemic.

Other prominent sceptics have been more soberingly analytical. Peter Ward and Donald Brownlee, in their book Rare Earth (Copernicus/Springer, 2000), discussed various factors that, on the face of it, conspire to make the emergence of life around stars probable but the appearance of intelligent species almost impossible. "Is that it?", one might ask when faced by the likelihood that we are, alas, the pinnacle of our Galaxy's intelligence. And according to a theory discussed at last week's meeting of the American Association for the Advancement of Science, if it wasn't for the chance mutation of the FOXP2 gene 50 millennia ago, we wouldn't have the creativity to explore these ideas.

Yet more cold water has been poured on our hopes that we have intelligent company in a recent collection of answers to Enrico Fermi's pointed question about the lack of visitors: "Where is everybody?".
In a sceptical book of that title (Copernicus/Springer, 2002), Stephen Webb's explanations for the absence of alien visitors range from: "They are here and they call themselves Hungarians", attributed to Budapest-born physicist Leo Szilard, to: "Science is not inevitable", science being one of many improbable developmental steps from primitive organisms to interstellar communication or travel.

A pox on such pan-Galactic pessimism. These arguments may give sober government agencies an excuse to stop funding searches for extraterrestrial intelligence (SETI), as the US Congress did over a decade ago. But the rest of us should look more favourably on such expressions of the fundamental yearnings of humanity. All credit to the likes of William Hewlett, David Packard and Paul Allen, whose funds have allowed the SETI projects to establish new technologiesalbeit still pitifully insensitive if we are to detect the equivalent of Friends leaking through some planetary ionosphere 1,000 light years away. All credit too to the tens of researchers who devote themselves to the dispiriting quest for such electromagnetic detritus. The rest of us should drag ourselves away from revivals of ET, Close Encounters and Taken long enough to scan the latest ambitions of the SETI institute, outlined in SETI 2020 (http://www.seti.org), and send it a donation for the hunt for the real Thing. 